\title{
Discovering Cultural Differences Through Information Flow of National DMOs Websites
}

\author{
Hyejin Park $^{(\bowtie)}$ and Svetlana Stepchenkova \\ Department of Tourism, Hospitality and Event Management, \\ University of Florida, Gainesville, FL, USA \\ hj2201@ufl.edu, svetlana.step@hhp.ufl.edu
}

\begin{abstract}
The purpose of the study is to investigate whether cultural differences are reflected in how destinations present themselves online by performing hyperlink network analysis of their official DMOs websites. The study examines whether variance in online presentation can be explained using well established theories on culture. To this end, hyperlink data were collected from three official tourism websites: Korea Tourism Organization (KTO) of South Korea, Brand USA of United States, and German National Tourist Board (GNTB) of Germany. The results show that the three hyperlink networks exhibit differences in size and structural properties. The information network of KTO tends to reflect collectivism, while those of Brand USA and GNTB reflect individualism. Blockmodeling analysis provides the grounds for further statistical approach.
\end{abstract}

Keywords: DMOs websites $\cdot$ Network analysis $\cdot$ Culture theory

\section{Introduction}

As all activities closely related to production in economy, art, technology, or education have fundamental realms of culture [1], cultural differences across societies or communities have always existed. Cultural impacts on tourist perception and behavior have been extensively investigated in many different contexts [2-5].

In the tourism field, websites are the important channels because they serve as the information hubs between the providers and consumers of destination tourism services $[6,7]$. Therefore, lots of tourism authorities employ the internet-based infrastructure to facilitate the exchange of information between stakeholders. Although the websites are full of information reflective of cultural peculiarities, the ways to leverage that cultural element have been limited. This study, which can be classified into the tourist information search domain, looks at the issue from a somewhat unusual angle: it focuses on how national tourist destination websites reflect cultural value system of their respective societies. One major growth engines of the websites is that users are able to search information by traversing throughout a set of hyperlinks [8-10]. This study examines the ways in which national destination websites build up the hyperlink structural network of destination stakeholders and communicate information through this network.

Specifically, the study posited the research question whether the cultural attributes underlie the information flow patterns of the web-linkages. The overall purpose of the 
study is to examine the structural idiosyncrasies of national DMOs websites using three national tourism websites - Korea Tourism Organization (KTO) of South Korea, Brand USA of United States, and German National Tourist Board (GNTB) of Germany.

\section{Literature Review}

Hofstede's studies [11-14] shed light on the embodiment of culture by suggesting cultural dimensions (e.g., Individualism-Collectivism, Uncertainty avoidance, Longterm (or Short term) orientation, Masculinity-Femininity, Power distance, and Indulgence-Restraint). Hall [15] claims that cultures can be classified as low or high context, depending on how important the context is to fully grasp the meaning of its communication. In high-context culture (e.g., China, Greece, Japan, South Korea, UAE), people are involved with each other and share strong intimacy. On the other hand, in low-context culture (e.g., Canada, Germany, Sweden, Switzerland, USA), the degree of involvement is low meaning that direct verbal information is required to communicate in daily life. Since their frameworks are well-known and due to limited space, detailed descriptions are omitted here. Briefly, South Korea is the society in which people appreciate the value of collectivism. They tend to be familiar with the commands from top-to-bottom approach. Power is centralized to authorities in a hierarchical order. When communicating with others, they express their opinions indirectly by utilizing nonverbal cues. On the other hand, in the United States, people value individual's freedom the most. They also place great emphasis on equality and transparency, so that they expect to get all information through open access in a direct communication way [16]. Even though German culture share some characteristics with American culture [17], not every cultural characteristic match that of the American. Germany presents a distinct departure from the American culture in terms of conflict resolution. According to Hall [15], Germans' management style to deal with conflict is quite blunt and rigorous, which seems averse to Americans. In sum, the United States and South Korea are located at opposite poles of cultural aspects, while Germany would be placed on between of these two countries.

Cultural variations have impacts on various online behaviors in tourism. Park and Reisinger [18] argued that national culture exerts an influence on web-communication behaviors such as information search, communication, and transaction behavior. Mele, Kerkhof [19] examined the effect of cultural localization on users' perceptions in webpages by adopting Individualism-Collectivism, and Power Distance dimensions in heritage tourism context. Cultural values could be reflected in the network structure on the web which (un)intentionally resonate with the values that permeate owners' culture $[6,10]$. Barnett and Sung [20] focused on the role of national culture as a webmechanism. They operationalized national culture as Hofstede's dimensions by the centrality and the overall structure of the hyperlink network. By analyzing data of 47 nations, they concluded that the national culture could explain the structure of the Internet. In tourism literature, one of the earliest studies conducted by Baggio, Scott [6] compared the structure of hyperlink network of tourism destinations assuming that the web system represents the economic and social group. Based on the literature, we 
assume that the cultural attributes embedded in DMOs websites might be associated with the layout of hyperlink network.

\section{Data Collection}

Three national DMOs websites were selected as the tourism information repositories to be influenced by cultural characteristics (see Table 1). For collecting hyperlink data, we follow the steps described by $\mathrm{Yi}$ and Scholz [21]. The hyperlinks of the websites were collected by using web-based crawler during late May and early June 2020. The overall network structures of each website were firstly quantified with the network indicators. In addition, blockmodeling analysis, a method of grouping similar nodes and condensing data into blocks based on the extent to which they are equivalent, was conducted to detect structural dissimilarity of information flow between networks.

Table 1. National DMOs websites as seed source

\begin{tabular}{l|l|l|l}
\hline & South Korea & Germany & United States \\
\hline $\begin{array}{l}\text { National } \\
\text { DMO }\end{array}$ & $\begin{array}{l}\text { Korea Tourism } \\
\text { Organization (KTO) }\end{array}$ & $\begin{array}{l}\text { German National Tourist } \\
\text { Board (GNTB) }\end{array}$ & Brand USA \\
\hline $\begin{array}{l}\text { Websites } \\
\text { URL }\end{array}$ & engligh.visitkorea.or.kr & www.germany.travel/en & $\begin{array}{l}\text { www. } \\
\text { visitusa.com }\end{array}$ \\
\hline
\end{tabular}

\section{Results}

\subsection{Overall Network Structure}

Table 2 presents overall properties of each hyperlink network. KTO has the largest network with the diameter value of 11 among three networks. The values of density of the networks were very low ranging from $1 \%$ to $2 \%$ indicating the direct interconnections between nodes in the whole network are very rare. A k-core analysis was applied to differentiate important actors for further analysis [22]. 3-kore in which we examine reciprocity and transitivity value was applied as cut-off point [23]. Among the 3-core networks, KTO network still has the largest network size with one giant component group. Overall, all three networks reveal quite low-density values same as in the whole networks. The KTO network is a much more collectivist network, with evidence of network size and the number of connected components. The KTO network could be characterized by collectivist network whose members share same cultural value in pursuit of a common goal. The Brand USA and GNTB, on the other hand, have much less hierarchized networks where a flatter structure is favored with more than 10 components. The networks of Brand USA and GNTB have more predominance of reciprocated hyperlinks over asymmetric connections than that of KTO meaning a more equal relation between members. The 3-core network properties of three DMOs networks are also provided in Table 2. 
Table 2. Whole \& 3-core network properties of three DMOs web-networks.

\begin{tabular}{l|l|l|l}
\hline Properties & KTO & GNTB & Brand USA \\
\hline \# of nodes & $592(1934)$ & $219(966)$ & $180(1456)$ \\
\hline \# of edges & $3465(6142)$ & $644(1612)$ & $664(2138)$ \\
\hline Avg. degree & $5.84(3.17)$ & $3.58(1.67)$ & $3.01(1.47)$ \\
\hline Diameter & $13(11)$ & $5(5)$ & $5(5)$ \\
\hline Density & $0.01(0.002)$ & $0.02(0.002)$ & $0.01(0.001)$ \\
\hline Reciprocity & 0.05 & 0.06 & 0.06 \\
\hline Transitivity & 0.20 & 0.54 & 0.65 \\
\hline Clustering coefficient & 0.35 & 0.65 & 0.59 \\
\hline Components & $1(1)$ & $7(15)$ & $3(20)$ \\
\hline
\end{tabular}

Note: The numbers in parentheses are the whole network properties of three DMOs networks

\subsection{Blockmodeling Analysis}

A blockmodeling analysis was also conducted to uncover structural dissimilarity between networks. It is useful into sorting hyperlinks into discrete clusters based on each unique block determined by a researcher [24]. In this study, 6 blocks which are Federal Level Government, State Level Government, Local Level Government, Social Media, Private Sector, and Association were identified. Next, block image matrix was dichotomized from block density matrix. Because of the lack of space, only data for the two networks with the most differences - KTO and Brand USA - are provided in Table 3. To evaluate how well the blockmodeling fits the identified categories, the goodness-of-fit for the hypothesized blockmodeling was also examined. All three blockmodels secure the adequacy of representation of each data set. Based on the two matrices, we generated reduced graphs (Fig. 1).

The result indicates that there are structural dissimilarities between three DMOs networks. With a predominance of asymmetric connections compared to the other networks, KTO network implies more of a hierarchy culture. Brand USA reflects their cultural characteristic that all information is distributed quite evenly, moreover, the blocks are all interconnected each other without no isolation. To some extent, the study found that there are more similarities than dissimilarities between KTO and GNTB. The findings of this study support many of earlier studies whose results argue that human activities have fundamentally realms of culture. 
Table 3. Density matrix of blockmodeling of three DMOs web-networks.

\begin{tabular}{l|l|l|l|l|l|l}
\hline KTO & Fed Gov. & State Gov. & Local Gov. & SNS & Private & Assoc. \\
\hline Fed Gov. & $0.017(1)$ & $0.006(0)$ & $0.006(0)$ & $0.003(0)$ & $0.004(0)$ & $0.004(0)$ \\
\hline State Gov. & $0.019(1)$ & $0.027(1)$ & $0.009(0)$ & $0.035(1)$ & $0.007(0)$ & $0.011(1)$ \\
\hline Local Gov. & $0.024(1)$ & $0.005(0)$ & $0.013(1)$ & $0.003(0)$ & $0.002(0)$ & $0.006(0)$ \\
\hline SNS & $0(0)$ & $0(0)$ & $0(0)$ & $0(0)$ & $0(0)$ & $0(0)$ \\
\hline Private & $0.007(0)$ & $0.004(0)$ & $0.002(0)$ & $0(0)$ & $0.01(0)$ & $0.004(0)$ \\
\hline Assoc. & $0.007(0)$ & $0.005(0)$ & $0.002(0)$ & $0.01(1)$ & $0.003(0)$ & $0.004(0)$ \\
\hline Brand USA & Fed Gov. & State Gov. & Local Gov. & SNS & Private & Assoc. \\
\hline Fed Gov. & $0.117(1)$ & $0.009(0)$ & $0.004(0)$ & $0(0)$ & $0.006(0)$ & $0.017(1)$ \\
\hline State Gov. & $0.016(1)$ & $0.036(1)$ & $0.009(0)$ & $0.144(1)$ & $0.016(1)$ & $0.008(0)$ \\
\hline Local Gov. & $0.024(1)$ & $0.006(0)$ & $0.013(0)$ & $0(1)$ & $0(1)$ & $0(1)$ \\
\hline SNS & $0(0)$ & $0(0)$ & $0(0)$ & $0(0)$ & $0(0)$ & $0(0)$ \\
\hline Private & $0.004(0)$ & $0.003(0)$ & $0.004(0)$ & $0.034(1)$ & $0.011(0)$ & $0.013(0)$ \\
\hline Assoc. & $0.003(0)$ & $0.005(0)$ & $0.012(0)$ & $0.018(1)$ & $0.011(0)$ & $0.013(0)$ \\
\hline
\end{tabular}

Note: The numbers in parentheses are dichotomized value for image matrix

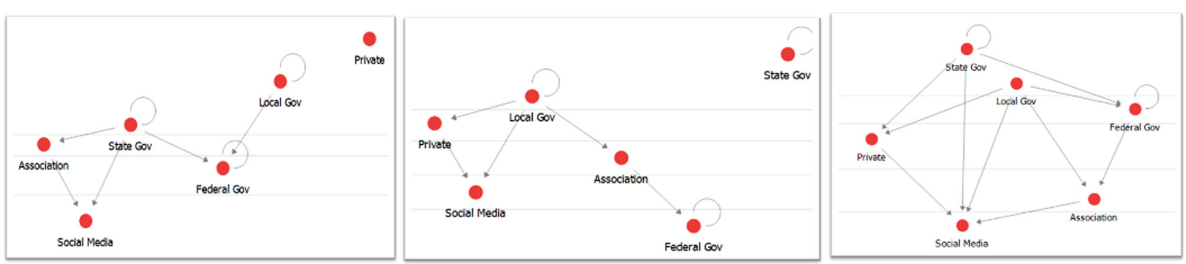

Fig. 1. Reduced graphs (KTO, GNTB and brand USA from left to right)

\section{Discussion}

The purpose of the study was to explore the structural idiosyncrasies of these websites which could impact on users' tourism information searching behavior. To this end, hyperlink network analysis was conducted on the data sets collected from three official tourism websites. Results indicated that the significance of structural hierarchy which was one common thread in the culture theories were associated with how the information is distributed. In the KTO network, rather than being evenly distributed among various players in the network, the number of links is concentrated in a limited number of subjects, governmental organizations, showing a structure in which power is concentrated. In the case of Brand USA and GNTB, actors other than the government share tourism information on the DMO platform, therefore, active information exchange was taking place among network participants.

Given the nature of tourism and destination branding, the target audiences are globally distributed. Accordingly, it is likely to cultural propensities would have a great influence the interaction between users and DMOs websites. For instance, a person in 
collectivistic culture would be more familiar with information created by top-down approach. We, therefore, assumed that the underlying cultural features of national DMOs websites could influence tourism information searching behavior or tourist satisfaction on websites. However, the study only unveils the evidence of different structural pattern of information flow based on cultural propensities. Therefore, future research should empirically examine how well users perceive the information patterns and how much it influences their decision-making process in tourism context. Also, it will be useful for researchers to explore more DMOs in same cultural sphere to draw validate conclusion.

\section{References}

1. Keesing RM (1974) Theories of culture. Annu Rev Anthropol 3(1):73-97

2. Choi S, Lehto XY, Oleary JT (2007) What does the consumer want from a DMO website? A study of US and Canadian tourists' perspectives. Int J Tour Res 9(2):59-72

3. Huang SS, Crotts J (2019) Relationships between Hofstede's cultural dimensions and tourist satisfaction: a cross-country cross-sample examination. Tour Manag 72:232-241

4. Kang DS, Mastin T (2008) How cultural difference affects international tourism public relations websites: a comparative analysis using Hofstede's cultural dimensions. Public Relat Rev 34(1):54-56

5. Stepchenkova S, Kim H, Kirilenko A (2015) Cultural differences in pictorial destination images: Russia through the camera lenses of American and Korean tourists. J Travel Res 54 (6):758-773

6. Baggio R, Scott N, Wang Z (2007) What network analysis of the WWW can tell us about the organisation of tourism destinations. In: CAUTHE 2007: Tourism-Past Achievements, Future Challenges, p 262

7. Tigre Moura F, Gnoth J, Deans KR (2015) Localizing cultural values on tourism destination websites: the effects on users' willingness to travel and destination image. J Travel Res 54 (4):528-542

8. Baggio R, Scott N, Cooper C (2010) Network science: a review focused on tourism. Ann Tour Res 37(3):802-827

9. Pan B, Fesenmaier DR (2006) Online information search: vacation planning process. Ann Tour Res 33(3):809-832

10. Park HW (2003) Hyperlink network analysis: a new method for the study of social structure on the web. Connections 25(1):49-61

11. Hofstede G (1993) Cultural constraints in management theories. Acad Manag Perspect 7 (1):81-94

12. Hofstede G (1984) Cultural dimensions in management and planning. Asia Pac J Manag 1 (2):81-99

13. Hofstede G (1980) Culture's Consequences: International Differences in Work-Related Values, vol 5. Sage

14. Hofstede G (2011) Dimensionalizing cultures: the Hofstede model in context. Online Read Psychol Cult 2(1):8

15. Hall ET (1976) Beyond culture. Anchor

16. Choi KS, Im I, Hofstede GJ (2016) A cross-cultural comparative analysis of small group collaboration using mobile twitter. Comput Hum Behav 65:308-318 
17. Wilde A, Diekman AB (2005) Cross-cultural similarities and differences in dynamic stereotypes: a comparison between Germany and the United States. Psychol Women Q 29 (2):188-196

18. Park S, Reisinger Y (2012) Cultural differences in tourism web communication: a preliminary study. Tour Anal 17(6):761-774

19. Mele E, Kerkhof P, Cantoni L (2020) Cultural localization in online heritage promotion. J Herit Tour, 1-17

20. Barnett GA, Sung E (2005) Culture and the structure of the international hyperlink network. J Comput Mediat Commun 11(1):217-238

21. Yi H, Scholz JT (2016) Policy networks in complex governance subsystems: observing and comparing hyperlink, media, and partnership networks. Policy Stud J 44(3):248-279

22. Borgatti SP, Everett MG, Johnson JC (2018) Analyzing Social Networks. Sage

23. Wasserman S, Faust K (1994) Social Network Analysis: Methods and Applications, vol 8. Cambridge University Press, Cambridge

24. Faust K, Wasserman S (1992) Blockmodels: interpretation and evaluation. Soc Netw 14(12):5-61

Open Access This chapter is licensed under the terms of the Creative Commons Attribution 4.0 International License (http://creativecommons.org/licenses/by/4.0/), which permits use, sharing, adaptation, distribution and reproduction in any medium or format, as long as you give appropriate credit to the original author(s) and the source, provide a link to the Creative Commons license and indicate if changes were made.

The images or other third party material in this chapter are included in the chapter's Creative Commons license, unless indicated otherwise in a credit line to the material. If material is not included in the chapter's Creative Commons license and your intended use is not permitted by statutory regulation or exceeds the permitted use, you will need to obtain permission directly from the copyright holder.

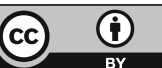

